\title{
Consumo, tempo de pastejo e desempenho de novilhos suplementados em pastos de Brachiaria decumbens, durante o período seco
}

\section{Intake, grazing time and performance of steers supplemented in Brachiaria decumbens pastures during the dry season}

\author{
Jocilaine Garcia ${ }^{1 *}$; Valéria Pacheco Batista Euclides²; Claudete Regina Alcalde ${ }^{3}$; \\ Gelson dos Santos Difante ${ }^{4}$; Sérgio Raposo de Medeiros ${ }^{5}$
}

\section{Resumo}

Objetivou-se avaliar a suplementação com sal mineral (SAL), sal mineral proteinado (SMP) e suplemento energético-protéico (SEP), fornecidos respectivamente, ad libitum, 0,2\% e 0,8\% do peso vivo (PV) sobre o consumo de matéria seca da forragem (CMSF), tempo de pastejo e desempenho de bovinos no período da seca (junho a agosto). O desempenho foi avaliado em 48 novilhos, com PV médio inicial de $310 \pm 50 \mathrm{~kg}$, distribuídos em 15 piquetes de Brachiaria decumbens, sendo o CMSF e o tempo de pastejo avaliados em 18 novilhos. Comparando com os animais consumindo SAL, o CMSF foi reduzido em $26 \%$ para aqueles suplementados com SEP, sem diferenciar dos animais suplementados com SMP. O tempo de pastejo foi reduzido em 16 e 90 minutos dia ${ }^{-1}$, para os animais suplementados respectivamente com SMP e com SEP, comparando com animais sem suplementação. Houve interação $(\mathrm{P}<0,01)$ tratamento $\mathrm{x}$ período para o ganho médio diário (GMD), não sendo diferente no mês inicial $\left(0,76 \mathrm{~kg}^{-}\right.$animal $^{-1}$ dia $\left.^{-1}\right)$, porém, no segundo mês, os animais do tratamento SAL ganharam $0,07 \mathrm{~kg}$ animal $^{-1}$ dia $^{-1}$, significativamente menos $(\mathrm{P}<0,01)$ do que os animais recebendo SMP e SEP, na qual o GMD foi de respectivamente 0,56 e $0,73 \mathrm{~kg}_{\text {animal }}{ }^{-1} \mathrm{dia}^{-1}$. A utilização da suplementação a pasto com SMP e SEP é interessante para se almejar maiores ganhos de peso de bovinos no período da seca, porém a suplementação com SMP não alterou o CMSF, sendo uma forma eficiente de fornecimento de nutrientes aos animais neste período.

Palavras-chave: Forragem, ganho de peso, proteína, suplemento

\begin{abstract}
The objective of this study was to evaluate the supplementation with mineral salt (SALT), proteic and mineral salt (PMS) and energetic-proteic supplement (EPS), respectively, provided ad libitum, $0.2 \%$ and $0.8 \%$ of body weight (BW) on dry matter forage intake (DMFI), grazing time and performance of cattle during the dry season (June to August). The performance was evaluated in 48 steers with an average initial BW of $310 \pm 50 \mathrm{~kg}$, distributed in 15 paddocks of Brachiaria decumbens, with the DMFI and grazing time evaluated in 18 steers. Compared with animals consuming SALT, the DMFI was reduced in $26 \%$ for those supplemented with EPS, without differences with the animals supplemented with PMS. Grazing time was reduced in 16 and 90 minutes day ${ }^{-1}$, respectively, for animals supplemented with PMS and EPS, compared to animals without supplementation. There was an interaction $(\mathrm{P}<0.01)$ treatment
\end{abstract}

1 Prof ${ }^{\text {a }}$, Universidade do estado de Mato Grosso, UNEMAT, Pontes e Lacerda, MT. E-mail: jo@unemat.br

2 Pesquisadora da EMBRAPA Gado de Corte, CNPGC, Campo Grande, MS. E-mail: valeria.pacheco@embrapa.br

3 Prof ${ }^{a}$, Universidade Estadual de Maringá, UEM, Maringá, PR. E-mail: cralcalde@wnet.com.br

4 Prof., Universidade Federal do Rio Grande do Norte, UFRN, Macaíba, RN. E-mail: difante@hotmail.com

5 Pesquisador, EMBRAPA Gado de Corte, CNPGC, Campo Grande, MS. E-mail: sergio@cnpgc.embrapa.br Autor para correspondência 
$\mathrm{x}$ period for average daily gain (ADG) not being different in the initial month $\left(0.76 \mathrm{~kg}\right.$ animal $\left.{ }^{-1} \mathrm{day}^{-1}\right)$, however, in the second month the animals receiving SALT gained $0.07 \mathrm{~kg}$ animal ${ }^{-1}$ day $^{-1}$, significantly $(\mathrm{P}<0.01)$ less than the animals of PMS and EPS, in which the ADG was 0.56 and $0.73 \mathrm{~kg}^{2}$ animal $^{-1} \mathrm{day}^{-1}$, respectively. The use of pasture supplementation with PMS and EPS is interesting to aim higher weight gains of cattle during the dry season, but supplementation with PMS did not alter the DMFI, being one efficient way to supply the nutrients to the animals during this period.

Key words: Forage, protein, supplement, weight gain

\section{Introdução}

A utilização da suplementação alimentar para animais em pastejo, têm-se tornado cada vez mais comum, e o principal fator que tem contribuído para isto é a sazonalidade na produção das forrageiras tropicais, que apresentam alta taxa de crescimento com melhor valor nutritivo no período chuvoso e, durante o período seco. Em consequência da estacionalidade no crescimento, há decréscimo na massa de forragem acompanhada de aumento nas frações indigestíveis, que resulta em decréscimo no valor nutritivo. Moraes et al. (2012) afirmaram que durante a estação da seca, a produção animal em pastagens tropicais é caracterizada pelo baixo desempenho ou pela perda de peso quando os animais não são suplementados.

Quando suplementos concentrados são incluídos na alimentação dos animais em pastejo, efeitos associativos relacionados ao consumo de forragem podem ocorrer, sendo esses efeitos tanto positivos ou aditivos (aumento), quanto negativos ou substitutivos (diminuição) (DIXON; STOCKDALE, 1999; MOORE et al., 1999; GOES et al., 2005; SILVA et al., 2009). A essas variações, no consumo de forragem, tem-se denominado de taxa ou coeficiente de substituição, que se refere à unidade variada na ingestão de forragem por unidade de suplemento ingerido (MOORE et al., 1999), sendo esse um dos principais fatores que explica a variação na resposta de desempenho animal (GOES et al., 2005).

Porém, verifica-se que ao se avaliar o efeito da suplementação sobre o desempenho de bovinos em pastejo, a maioria dos resultados é positiva, ou seja, as características de produção têm aumentado como resultado da suplementação tanto energética quanto protéica ou de ambas (ZERVOUDASKIS et al., 2002; BODINE; PURVIS, 2003; TITGEMEYER et al., 2004; GOES et al., 2005; GOES et al., 2010; SIMIONI et al., 2009; LIMA et al., 2012), pois o uso de suplementação concentrada, pode gerar melhor aproveitamento da forrageira disponível, e aprimorar o desempenho animal (GOES et al., 2010).

Silva et al. (2009) alertaram que níveis de suplementação acima de $0,2 \%$ do $\mathrm{PV}$, podem promover reduções no consumo de forragem, e níveis acima de $0,8 \%$ do PV devem ser utilizados com alternativas que possam evitar possíveis efeitos negativos no ambiente ruminal que, por consequência, pode reduzir as expectativas de ganho de peso.

O objetivo deste trabalho foi avaliar o efeito da suplementação com sal mineral proteinado e suplemento energético-protéico sobre o consumo de forragem, tempo de pastejo e desempenho de bovinos mantidos em pastagens de Brachiaria decumbens, no período da seca.

\section{Material e Métodos}

$\mathrm{O}$ experimento foi conduzido no Centro Nacional de Pesquisa de Gado de Corte (CNPGC), da Empresa Brasileira de Pesquisa Agropecuária (EMBRAPA), localizada em Campo Grande - MS, no período da seca (junho a setembro). A região apresenta temperaturas médias que variam de 14 a $33^{\circ} \mathrm{C}$ e precipitação média anual de $1500 \mathrm{~mm}$.

Os tratamentos constituíram-se das suplementações: sal mineral (SAL), ad libitum; sal 
mineral proteinado (SMP) e suplemento energéticoprotéico (SEP), fornecidos respectivamente a $0,2 \%$ e $0,8 \%$ do peso vivo (PV). Os suplementos foram pesados e fornecidos individualmente, sendo divididos em duas porções diárias $(08 \mathrm{~h} 30 \mathrm{~min}$ e 14h30min). A proporção dos ingredientes em cada tratamento e a composição química dos suplementos está demonstrada na Tabela 1.

Tabela 1. Proporção dos ingredientes expressos na base da matéria natural e composição química dos suplementos.

\begin{tabular}{lcll}
\hline & \multicolumn{3}{c}{ Tratamentos $^{1}$} \\
\cline { 2 - 4 } Componentes & SAL & SMP & SEP \\
\hline Milho grão & - & 40,0 & 34,0 \\
Casca de soja & - & - & 28,8 \\
Soja grão & - & - & 23,8 \\
Farelo de algodão 38\% & - & 30,0 & 11,2 \\
Uréia & - & 9,8 & - \\
Sulfato de amônio & - & 1,0 & - \\
Sal mineral & & 9,0 & 1,28 \\
Calcário calcítico & 100,0 & - & 0,86 \\
Cloreto de sódio & - & 10,0 & - \\
Rumensin & - & 0,2 & 0,06 \\
\hline Composição Química (\%) & - & & 89,60 \\
\hline Matéria seca (MS \%) & & 88,50 & 82,60 \\
Matéria orgânica (\% da MS) & - & 66,50 & 21,60 \\
Proteína bruta (\% da MS) & - & 56,30 & 32,90 \\
Fibra em detergente neutro (\% da MS) & - & 9,20 & 24,30 \\
Fibra em detergente ácido (\% da MS) & - & 5,60 & 7,30 \\
Extrato etéreo (\% da MS) & - & 2,40 & \\
\hline
\end{tabular}

1.Tratamentos: sal mineral (SAL); sal mineral proteinado (SMP), suplemento energético-protéico (SEP)

${ }^{2}$ Composição percentual: cloreto de sódio, 48,75; fosfato bicálcico, 39,26; flor de enxofre, 7,36; sulfato de zinco, 3,90; sulfato de cobre, 0,70 ; iodeto de potássio, 0,015 ; sulfato de cobalto, 0,014; selenito de sódio, 0,008 .

Fonte: Elaboração dos autores.

O desempenho foi avaliado em 48 novilhos ( $1 \frac{2}{2}$ Braford x $1 / 4$ Angus x $1 / 4$ Nelore), castrados, com idade média inicial de 20 meses e peso vivo médio de $311 \mathrm{~kg}( \pm 50 \mathrm{~kg})$. Os animais foram distribuídos aleatoriamente em 15 piquetes de Brahiaria decumbens cv. Basilisk (12 piquetes de 0,75 ha e três piquetes de 1,0 ha). Todos os piquetes foram providos com bebedouros e cochos para fornecimento de sal mineral e suplementos.

O delineamento experimental foi inteiramente casualizado, com três tratamentos, cinco repetições com três animais por repetição nos piquetes de 0,75 ha, e quatro animais nos piquetes de 1,0 ha. Os animais foram pesados no início do experimento e a cada mês (período), com a finalidade de avaliar o ganho de peso médio diário por animal. Os pesos foram obtidos após jejum de alimento e de água de 16 horas.

A disponibilidade de matéria seca da forragem total foi estimada, em cada período, cortando-se a forragem (nível do solo) em quadrados de $1 \mathrm{~m}^{2}$. As amostras foram pesadas individualmente e após a pesagem, cada amostra foi dividida em duas partes, sendo uma seca em estufa a $65^{\circ} \mathrm{C}$ e pesada para calcular a disponibilidade de matéria seca total; e a outra utilizada para formar sub-amostras compostas que foram separadas em folha verde, colmo verde e material senescente.

A determinação do consumo de forragem foi realizada utilizando 18 animais, sendo três animais por piquete, e dois piquetes por tratamento. No 
período de avaliação, foi realizada a amostragem do pasto por intermédio de simulação de pastejo (MORAES et al., 2005) por dois amostradores, com o objetivo de avaliar a forragem ingerida pelos animais. As amostras foram analisadas utilizando espectroscopia de reflectância do infra-vermelho próximo (NIRS), seguindo os procedimentos de Marten, Shenk e Barton (1989).

O consumo foi estimado, aplicando no rúmen 10 g de óxido crômico, divididas em duas aplicações diárias, às 05 horas e às 17 horas, por 12 dias (sete de adaptação e cinco de coleta de fezes), conforme a metodologia proposta por Hopper, Holloway e Butts Júnior (1978). As amostras de fezes foram secas em estufa a $65^{\circ} \mathrm{C}$, pesadas e moídas $(1 \mathrm{~mm})$ e compostas com base no peso seco ao ar, por tratamento e período, e analisadas quanto ao teor de cromo (WILLIAMS; DAVID; ISMAA, 1962). A produção de MS fecal $\left(\mathrm{kg} \mathrm{dia}^{-1}\right)$ foi calculada com base no $\mathrm{Cr}_{2} \mathrm{O}_{3}$ fornecido $\left(\mathrm{g} \mathrm{dia}^{-1}\right) / \mathrm{Cr}_{2} \mathrm{O}_{3}$ nas fezes $(\mathrm{g}$ $\mathrm{kg}$ de $\mathrm{MS}^{-1}$ ).

Utilizou-se a fibra em detergente neutro indigestível (FDNi) como indicador interno, de acordo com a metodologia empregada por Lippke, Ellis e Jacobs (1986). As estimativas do consumo foram obtidas pela seguinte equação:

$\mathrm{CMS}\left(\mathrm{kg} \mathrm{dia}^{-1}\right)=\{[(\mathrm{PF} * \mathrm{CIF})-\mathrm{IS}] / \mathrm{CIFO}\}+\mathrm{CMSS}$ em que:

$\mathrm{CMS}=$ consumo de matéria seca $\left(\mathrm{kg} \mathrm{dia}{ }^{-1}\right)$;

$\mathrm{PF}=$ produção de MS fecal $\left(\mathrm{kg} \mathrm{dia}^{-1}\right)$;

$\mathrm{CIF}=$ concentração do indicador nas fezes $(\mathrm{kg} \mathrm{kg}$ de $\left.\mathrm{MS}^{-1}\right)$;

IS = indicador presente no suplemento $\left(\mathrm{kg} \mathrm{dia}^{-1}\right)$;

$\mathrm{CIFO}=$ concentração do indicador na forragem $(\mathrm{kg}$ $\mathrm{kg}$ de $\mathrm{MS}^{-1}$ );

CMSS = consumo de matéria seca do suplemento $\left(\mathrm{kg} \mathrm{dia}{ }^{-1}\right)$.

O tempo de pastejo (minutos $\mathrm{dia}^{-1}$ ) foi determinado acoplando em cada animal, um aparelho Vibracorder (tacógrafo acoplado a um buçal) (STOBBS, 1970). Para a determinação do tempo de pastejo foram utilizados 18 animais (três animais por piquete, e dois piquetes por tratamento).

Os valores de ganho médio diário foram interpretados por meio de análises de variância, segundo o modelo estatístico 1 e consumo total, de forragem e de nutrientes, bem como o tempo de pastejo foram interpretados por meio de análises de variância segundo o modelo estatístico 2, sendo utilizado o programa estatístico SAS (Statistical Analysis System, versão 8).

$$
\begin{gathered}
\text { Modelo 1: } \mathrm{Y}_{\mathrm{ijk}}=\mu+\mathrm{T}_{\mathrm{i}}+\mathrm{P}_{\mathrm{j}}+\mathrm{T}_{\mathrm{i}} * \mathrm{P}_{\mathrm{j}}+\mathrm{e}_{\mathrm{ijk}} \\
\text { Modelo 2: } \mathrm{Y}_{\mathrm{ij}}=\mu+\mathrm{T}_{\mathrm{i}}+\mathrm{e}_{\mathrm{ij}}
\end{gathered}
$$

Em que:

$\mathrm{Y}_{\mathrm{ij}}=$ valor observado relativo ao tratamento i, e a repetição j;

$\mathrm{Y}_{\mathrm{ijk}}=$ valor observado relativo ao tratamento $\mathrm{i}$, ao período j e a repetição k;

$\mu=$ média geral;

$\mathrm{T}_{\mathrm{i}}=$ efeito do tratamento $\mathrm{i}$, sendo $\mathrm{i}=1,2$ e 3 ;

$P_{j}=$ efeito do período $j$, sendo $j=1$ e 2 ;

$\mathrm{T}_{\mathrm{i}} \mathrm{P}_{\mathrm{j}}=$ efeito da interação entre o tratamento i e o período $\mathrm{j}$;

$\mathrm{e}_{\mathrm{ij}} \mathrm{ou}_{\mathrm{ijk}}=$ erro aleatório, associado a cada observação.

\section{Resultados e Discussão}

Não houve interação entre tratamento e período $(\mathrm{P}>0,05)$ para as disponibilidades $\left(\mathrm{kg} \mathrm{ha}^{-1}\right.$ de $\left.\mathrm{MS}\right)$ de matéria seca total (MST), de material verde (MV), e de lâminas foliares verdes (LFV), bem como proporção (\%) de lâminas foliares (LF), pseudocolmos (PC) e material senescente (MSe). Também, para as mesmas características, não foram verificadas diferenças $(\mathrm{P}>0,05)$ entre os tratamentos 
(Tabela 2). Isso demonstra que se as pastagens, entre os tratamentos apresentaram valores semelhantes de disponibilidade de MST e de MV, durante esse período, as características do pasto não poderiam interferir no consumo, tempo de pastejo e desempenho dos animais.

Quando avaliado entre os meses experimentais (Tabela 2), apenas a disponibilidade de MST não foi alterada $(P>0,05)$. A disponibilidade de MV e de
LFV reduziram $(\mathrm{P}<0,01)$ com o avançar dos meses, mas observa-se que em ambos os casos, as diferenças foram entre os meses de junho comparando com julho e agosto, que não foram diferentes $(\mathrm{P}>0,05)$ entre si. Isto é um reflexo da alteração na proporção entre LF, PC e MSe (Tabela 2) pois a quantidade de LF e PC reduziram $(\mathrm{P}<0,05)$ com o avançar dos meses, aumentando $(\mathrm{P}<0,05)$ inversamente a proporção de MSe.

Tabela 2. Médias e coeficientes de variação (CV\%) da disponibilidade $\left(\mathrm{kg} \mathrm{ha}^{-1}\right)$ de matéria seca total (MST), de material verde (MV) e de lâminas foliares verdes (LFV) e proporções (\%) de lâminas foliares (LF), pseudocolmos (PC) e material senescente (MSe) entre os tratamentos e os meses experimentais.

\begin{tabular}{|c|c|c|c|c|c|c|}
\hline & \multicolumn{3}{|c|}{ Disponibilidade $\left(\mathrm{kg} \mathrm{ha}^{-1}\right)$} & \multicolumn{3}{|c|}{ Proporção (\%) } \\
\hline & MST & MV & LFV & LF & $\mathrm{PC}$ & $\mathrm{MSe}$ \\
\hline \multicolumn{7}{|c|}{ Tratamentos $^{1}$} \\
\hline SAL & $5522 \mathrm{a}$ & $2383 \mathrm{a}$ & $842 \mathrm{a}$ & $15,07 \mathrm{a}$ & $30,34 \mathrm{a}$ & $54,68 \mathrm{a}$ \\
\hline SMP & $4540 \mathrm{a}$ & $2459 \mathrm{a}$ & $895 \mathrm{a}$ & $20,80 \mathrm{a}$ & $34,86 \mathrm{a}$ & $44,34 \mathrm{~b}$ \\
\hline SEM & $4880 \mathrm{a}$ & $2520 \mathrm{a}$ & $851 \mathrm{a}$ & $18,10 \mathrm{a}$ & 30,17 a & $51,73 \mathrm{a}$ \\
\hline $\mathrm{CV} \%$ & 29,67 & 25,87 & 26,97 & 29,94 & 20,28 & 16,21 \\
\hline \multicolumn{7}{|l|}{ Meses } \\
\hline Junho & $5006 \mathrm{a}$ & $3875 \mathrm{a}$ & $1780 \mathrm{a}$ & $37,17 \mathrm{a}$ & $40,54 \mathrm{a}$ & $22,29 \mathrm{c}$ \\
\hline Julho & $4851 \mathrm{a}$ & $2237 \mathrm{~b}$ & $584 \mathrm{~b}$ & $12,24 \mathrm{~b}$ & $34,02 \mathrm{~b}$ & $53,74 \mathrm{~b}$ \\
\hline Agosto & $5085 \mathrm{a}$ & $1250 \mathrm{~b}$ & $224 b$ & $4,56 \mathrm{c}$ & $20,81 \mathrm{c}$ & $74,72 \mathrm{a}$ \\
\hline $\mathrm{CV} \%$ & 21,93 & 29,20 & 35,96 & 38,76 & 22,28 & 18,02 \\
\hline
\end{tabular}

1.Tratamentos: sal mineral (SAL); sal mineral proteinado (SMP), suplemento energético-protéico (SEP)

Médias, seguidas por letras distintas na mesma coluna, são diferentes $(\mathrm{P}<0,05)$ pelo Teste de Tukey.

Fonte: Elaboração dos autores.

A média de disponibilidade de MST de $4981 \mathrm{~kg}$ ha $^{-1}$ de MS está acima do estipulado por Minson (1990), de 2000 ( $\mathrm{kg} \mathrm{ha}^{-1}$ de MS), como sendo o mínimo para que a disponibilidade de MST não ocasione diminuição no consumo do pasto, além de não oferecer limitação à capacidade seletiva dos animais, pois $4262 \mathrm{~kg} \mathrm{ha}^{-1}$ de MST (EUCLIDES; MACEDO; OLIVEIRA, 1992) e $2500 \mathrm{~kg} \mathrm{ha-1}$ de MV (EUCLIDES et al., 1998) disponíveis de Brachiaria decumbens seriam satisfatórios para garantir o pastejo seletivo.

Inicialmente, cerca de $80 \%$ da MST disponível era constituída por MV, reduzindo para $20 \%$ no final do período experimental, indicando na entrada dos animais, que cerca de $80 \%$ da disponibilidade MST era constituída de MV, componente mais procurado pelos animais em pastejo, principalmente no período da seca. Em estudo com Brachiaria decumbens, Moraes et al. (2005) verificaram diminuição na disponibilidade de MV, de $2310 \mathrm{~kg} \mathrm{ha}^{-1}$ para 1011 $\mathrm{kg} \mathrm{ha}^{-1}$, justificando o comportamento do animal em selecionar uma dieta de melhor valor nutritivo.

$\mathrm{O}$ valor nutritivo da forragem ingerida pelos animais, obtida por meio de simulação de pastejo, não diferenciou $(\mathrm{P}>0,05)$ para o teor em proteína bruta (PB), fibra em detergente neutro (FDN), lignina detergente ácido (LDA) e digestibilidade in vitro da matéria orgânica (DIVMO) entre os tratamentos (Tabela 3). Porém, entre os meses avaliados, houve redução $(\mathrm{P}<0,01)$, no teor de $\mathrm{PB}$ 
e na $\mathrm{D} I V \mathrm{MO}$, com aumentos $(\mathrm{P}<0,01)$ nos teores de FDN e LDA (Tabela 3). Pode-se observar que o teor de PB do pasto de Brachiaria decumbens cv. Basilisk no mês de julho foi em média de $6,6 \%$, cujo valor está abaixo de 7\%, que é limitante para adequada atividade e crescimento microbiano no rúmen, conforme preconizado por Minson (1990), e posteriormente confirmado por Lazarinni et al. (2009) e Goes et al. (2010).
Avaliando as características da Brachiaria decumbens, no período seco, Moraes et al. (2012) verificaram níveis de $\mathrm{PB}$ abaixo de $7 \%$, e elevados teores em FDN, FDA e lignina, justificando uma consequência natural da avançada maturidade fisiológica do pasto, pois à medida que a idade fisiológica da planta avança, aumentam as concentrações dos carboidratos estruturais e ocorre maior conteúdo de lignina na parede celular vegetal.

Tabela 3. Médias e coeficientes de variação (CV\%) dos teores de proteína bruta (PB), fibra em detergente neutro (FDN) e lignina detergente ácido (LDA), e digestibilidade in vitro da matéria orgânica (DIVMO) da Brachiaria decumbens coletada por meio de simulação de pastejo.

\begin{tabular}{|c|c|c|c|c|c|c|c|}
\hline \multirow[b]{2}{*}{ Descrição } & \multicolumn{3}{|c|}{ Tratamentos ${ }^{1}$} & & \multicolumn{2}{|c|}{ Períodos } & \multirow[b]{2}{*}{$\mathrm{CV}(\%)$} \\
\hline & SAL & SMP & SEP & $\mathrm{CV}(\%)$ & Junho & Julho & \\
\hline PB & 8,18 & 8,60 & 8,51 & 23,29 & $10,25 \mathrm{a}$ & $6,60 \mathrm{~b}$ & 7,30 \\
\hline FDN & 71,32 & 70,98 & 70,90 & 2,76 & $70,01 \mathrm{~b}$ & $72,12 \mathrm{a}$ & 2,29 \\
\hline LDA & 3,58 & 3,32 & 3,51 & 17,16 & $3,00 \mathrm{~b}$ & $3,93 \mathrm{a}$ & 10,79 \\
\hline $\mathrm{D} I V \mathrm{MO}$ & 53,72 & 54,81 & 54,59 & 11,93 & $60,15 \mathrm{a}$ & $48,59 \mathrm{~b}$ & 4,87 \\
\hline
\end{tabular}

${ }^{1}$ Tratamentos: sal mineral (SAL); sal mineral proteinado (SMP), suplemento energético-protéico (SEP)

Médias, seguidas por letras distintas na mesma linha, são diferentes $(\mathrm{P}<0,05)$ pelo Teste de Tukey.

Fonte: Elaboração dos autores.

Foram observados consumos de matéria seca total (CMST) de 4,74; 4,67 e 5,83 $\mathrm{kg}$ animal $^{-1} \mathrm{dia}^{-1}$, respectivamente para os animais do tratamento SAL, SMP e SEP, que consumiram, dessa forma, 4,74; 4,09 e 3,51 kg animal-1 dia $^{-1}$ de forragem (CMSF). Os valores são próximos aos encontrados por Goes et al. (2010), ao suplementar novilhos em pastos de Brachiaria brizantha, no período da seca, nos níveis de $0 ; 0,125 ; 0,25 ; 0,5$ e $1,0 \%$ do PV, e verificaram respectivos consumos de 4,21; 5,40; 4,$81 ; 5,66$ e $3,89 \mathrm{~kg}_{\text {animal }}{ }^{-1} \mathrm{dia}^{-1}$.

Os dados de consumo médio diário expresso em $\%$ do PV podem ser visualizados na Tabela 4 . O CMST (\% do PV) não diferenciou $(\mathrm{P}>0,05)$ entre os tratamentos. Entretanto, os animais suplementados apenas com sal mineral consumiram mais forragem $(\mathrm{P}<0,05)$ do que os animais suplementados com SEP. Nos animais que receberam SMP, o CMSF foi semelhante $(\mathrm{P}>0,05)$ ao dos animais recebendo SAL e SEP.

Os valores de CMST foram próximos aos verificados por Simioni et al. (2009), ao suplementarem bovinos com os níveis de $0,6 \%$ do $\mathrm{PV}$ e $0,3 \%$ do PV, relatando CMST, respectivos, de 1,76 e 1,56\% do PV. Os pesquisadores também verificaram que o CMSF pelos animais sob suplementação, em relação àqueles que receberam apenas mistura mineral, foi menor (1,27 vs $1,49 \%$ do PV), notando-se um aumento no CMST de acordo com a quantidade de suplemento ingerida, mesmo com a redução no CMSF. 
Tabela 4. Médias e coeficientes de variação (CV\%) dos consumos de matéria seca total (CMST) e da forragem (CMSF), de proteína bruta total (CPBT) e da forragem (CPBF), de fibra em detergente neutro total (CFDNT) e da forragem (CFDNF) em \% do PV.

\begin{tabular}{lcccc}
\hline \multirow{2}{*}{ Consumo } & \multicolumn{4}{c}{ Tratamentos } \\
\cline { 2 - 5 } & SAL & SMP & SEP & CV\% \\
\hline CMST & $1,46 \mathrm{a}$ & $1,46 \mathrm{a}$ & $1,79 \mathrm{a}$ & 14,28 \\
CMSF & $1,46 \mathrm{a}$ & $1,27 \mathrm{ab}$ & $1,08 \mathrm{~b}$ & 16,87 \\
CPBT & $0,09 \mathrm{c}$ & $0,19 \mathrm{~b}$ & $0,23 \mathrm{a}$ & 10,09 \\
CPBF & $0,09 \mathrm{a}$ & $0,09 \mathrm{a}$ & $0,07 \mathrm{a}$ & 16,47 \\
CFDNT & $1,07 \mathrm{a}$ & $0,92 \mathrm{a}$ & $1,01 \mathrm{a}$ & 15,92 \\
CFDNF & $1,07 \mathrm{a}$ & $0,91 \mathrm{ab}$ & $0,78 \mathrm{~b}$ & 17,09 \\
\hline
\end{tabular}

1.Tratamentos: sal mineral (SAL); sal mineral proteinado (SMP), suplemento energético-protéico (SEP)

Médias, seguidas por letras distintas na mesma linha, são diferentes $(\mathrm{P}<0,05)$ pelo Teste de Tukey.

Fonte: Elaboração dos autores.

Pelos resultados obtidos para CMSF, observase que houve efeito substitutivo do consumo de forragem pelo fornecimento do suplemento sendo esta redução de $13 \%$ e de $26 \%$ para os animais suplementados com SMP e SEP, respectivamente. Poderia se esperar que houvesse um efeito aditivo, principalmente ao se utilizar o suplemento mineral protéico, pois, de acordo com Goes et al. (2005), o efeito aditivo com estímulo seria aquele em que o consumo de suplemento estimularia o de forragem como acontece quando da utilização de suplementos protéicos, em pastagens de baixa qualidade, em que a proteína favorece a ação dos microrganismos que auxiliam a digestão das forragens, ocasionando melhor aproveitamento pelo animal.

Em revisão realizada por Silva et al. (2009), utilizando trabalhos publicados no Brasil, os pesquisadores verificaram que ocorreu tendência de redução do consumo de forragem quando a ingestão de suplemento supera os níveis de 0,2-0,3\% do PV, demonstrando o efeito substitutivo da forragem pelo suplemento a partir destes níveis de fornecimento.

Goes et al. (2005) também verificaram redução no CMSF ao utilizarem suplementação energéticaprotéica a $1,0 \%$ do $\mathrm{PV}$, comparando com animais recebendo apenas suplementação mineral, sem verificarem alteração no CMST. Inversamente, tanto Lima et al. (2012) quanto Porto et al. (2009) notaram, ao utilizar suplementação para bovinos em pastejo um efeito aditivo, sem substituição no consumo de forragem.

O CPBT (Tabela 4) foi maior $(\mathrm{P}<0,01) \mathrm{em}$ animais suplementados com SEP, seguidos dos animais suplementados com SMP e daqueles recebendo SAL. Isso ocorreu pelo fato dos animais consumirem maiores teores de $\mathrm{PB}$ via suplementação, e principalmente pelo nível de suplementação SEP (0,8\% do PV) ser superior ao $\operatorname{SMP}(0,2 \%$ do PV). O CPBF não foi alterado $(\mathrm{P}>0,05)$ pelos tratamentos.

Segundo o NRC (1996), um animal dessa categoria, ganhando em torno de $0,4 \mathrm{~kg} \mathrm{dia}^{-1}$, exige um consumo diário de $\mathrm{PB}$ em torno de $0,2 \%$ do PV. Contudo, observa-se que, sem a suplementação os animais não conseguiram alcançar suas exigências de ganho, pois o CPBT foi de aproximadamente, $0,1 \%$ do PV. Valores de PB abaixo da exigência do animal impossibilitam que a reciclagem de nitrogênio no rúmen compense o baixo teor de $\mathrm{PB}$ da pastagem. Nesse caso, recomenda-se a suplementação protéica para se aumentar a concentração de $\mathrm{N}$-amoniacal no rúmen, a fim de se potencializar o consumo de forragem (GOES et al., 2010). Lazarinni et al. (2009) comentaram que a suplementação com compostos nitrogenados que eleva o conteúdo em PB da dieta para níveis próximos a $11 \%$ otimiza o uso de forrageiras de baixa qualidade. 
Os suplementos também não reduziram $(\mathrm{P}>0,05)$ o CFDNT (Tabela 4), porém, o CFDNF foi menor $(\mathrm{P}<0,05)$ apenas para os animais suplementados com SEP, comparados aos animais suplementados com SAL. Os animais que receberam SMP consumiram semelhantes $(\mathrm{P}>0,05)$ quantidades de FDN, comparados aos animais dos tratamentos SAL e SEP. Essa diferença para os animais suplementados com SEP ocorreu porque os animais deste grupo consumiram menores quantidades de MS de forragem. Pode ser notado, também, que o consumo de FDN foi inferior a 1,8\%, sendo esta característica um fator limitante do consumo de Brachiaria decumbens (EUCLIDES et al., 2000).

Goes et al. (2010) também verificaram baixo consumo de FDN (1,12\% do PV animal) ao suplementar novilhos, e de acordo com os pesquisadores, esse resultado sugere que o consumo voluntário de MS no período estudado foi limitado pela repleção ruminal, em decorrência da baixa qualidade da forragem consumida.

Suplementando tourinhos em fase de recria, no período da seca, Porto et al. (2011) verificaram que houve menor participação do pasto como fonte de energia à medida que aumentava o fornecimento de suplemento, evidenciando que as menores ofertas de suplemento e os altos teores de PB em suplementos múltiplos de baixo consumo propiciam maior uso da forragem como fonte de energia, ou seja, maior consumo da dieta basal, recomendando que a suplementação para baixo consumo (aproximadamente $0,2 \%$ do PV) pode ser fornecida aos tourinhos em fase de recria durante o período da seca para estimular o consumo de pasto, porém a máxima produção microbiana é obtida com ofertas medianas de suplementos (aproximadamente 0,5\% do PV).

No período da seca, a utilização do SEP reduziu $(\mathrm{P}<0,07)$ o tempo de pastejo dos animais (Figura 1), comparando com os animais que foram suplementados apenas com SAL, e ambos não diferenciaram do tempo de pastejo exibido pelos animais suplementados com SMP. As médias de tempo de pastejo foram de 633 (10h55min), 617 (10h28min) e 543 (9h05min) minutos dia $^{-1}$, respectivamente, para os animais suplementados com SAL, SMP e SEP, representando reduções no tempo de pastejo de 16 e de 90 minutos dia ${ }^{-1}$, em animais suplementados com SMP e com SEP, respectivamente.

Estes resultados estão de acordo com o que foi proposto por Minson (1990), em que as reduções no tempo de pastejo de animais suplementados poderiam explicar a taxa de substituição. $\mathrm{O}$ mesmo autor ainda comenta que ocorre uma redução de 12 minutos por dia por $\mathrm{kg}$ de concentrado fornecido. De acordo com este experimento, os animais reduziram 39 minutos por dia por $\mathrm{kg}$ de suplemento fornecido.

Figura 1. Tempo de pastejo (minutos dia ${ }^{-1}$ ) de novilhos cruzados, pastejando Brachiaria decumbens, no período da seca, em função das suplementações (SAL - Sal mineral; SMP - Suplemento mineral protéico; SEP Suplemento energético-protéico).

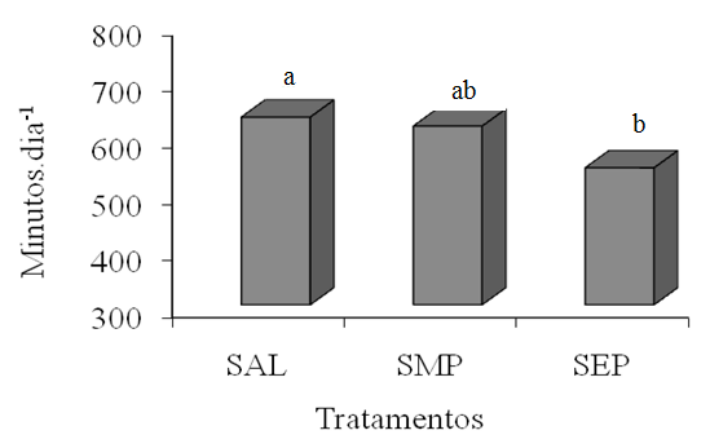

Fonte: Elaboração dos autores.

O tempo de pastejo varia de sete a doze horas, e um longo tempo de pastejo é indicativo de que o consumo está sendo limitado pelas características estruturais da forragem, que dificultam a seleção e a facilidade de preensão da forrageira (EUCLIDES et al., 2000). O mesmo é confirmado por Santos et al. (2004) que comentam que em determinadas situações, pode ser verificado aumento do tempo de pastejo e do gasto de energia pelo animal, associados ao declínio do CMS e da qualidade do pasto ingerido, em resposta também às alterações 
na estrutura do relvado, ou seja, em decorrência de redução da densidade de folhas verdes na forragem disponível e do aumento do grau de dificuldade para o animal selecionar os componentes do relvado de melhor qualidade.
Houve interação entre tratamento e período $(\mathrm{P}<0,01)$ para o ganho médio diário dos animais (GMD - $\mathrm{kg}_{\text {animal }}{ }^{-1} \mathrm{dia}^{-1}$ ). No primeiro período que compreenderam os meses de junho a julho, os diferentes tratamentos não alteraram significativamente o GMD, com valor médio de $0,76 \mathrm{~kg}_{\text {animal }}{ }^{-1} \mathrm{dia}^{-1}$ (Tabela 5).

Tabela 5. Médias e erros-padrão de peso vivo médio inicial e final e ganho médio diário de novilhos em pastagens de Brachiaria decumbens, de acordo com os tratamentos e períodos experimentais.

\begin{tabular}{|c|c|c|c|c|}
\hline \multirow[b]{2}{*}{ Descrição } & \multicolumn{3}{|c|}{ Tratamentos $^{1}$} & \multirow[b]{2}{*}{ Média/Per } \\
\hline & SAL & SMP & SEP & \\
\hline & \multicolumn{4}{|c|}{ Peso Vivo (PV) } \\
\hline PV Inicial & $310 \pm 29$ & $310 \pm 32$ & $311 \pm 33$ & $310 \pm 31$ \\
\hline \multirow[t]{2}{*}{ PV Final } & $337 \pm 33$ & $352 \pm 33$ & $364 \pm 41$ & $351 \pm 36$ \\
\hline & \multicolumn{4}{|c|}{ GMD $\left(\mathrm{kg}\right.$ animal $\left.{ }^{-1} \mathrm{dia}^{-1}\right)$} \\
\hline Junho-julho & $\begin{array}{l}0,75 \mathrm{Aa} \\
( \pm 0,25)\end{array}$ & $\begin{array}{l}0,70 \mathrm{Aa} \\
( \pm 0,18)\end{array}$ & $\begin{array}{l}0,84 \mathrm{Aa} \\
( \pm 0,27)\end{array}$ & $\begin{array}{c}0,76 \mathrm{a} \\
( \pm 0,24)\end{array}$ \\
\hline Julho-agosto & $\begin{array}{l}0,07 \mathrm{Bb} \\
( \pm 0,29)\end{array}$ & $\begin{array}{l}0,56 \mathrm{Aa} \\
( \pm 0,21)\end{array}$ & $\begin{array}{l}0,73 \mathrm{Aa} \\
( \pm 0,25)\end{array}$ & $\begin{array}{c}0,45 \mathrm{~b} \\
( \pm 0,33)\end{array}$ \\
\hline Média/Trat & $\begin{array}{c}0,41 \text { B } \\
( \pm 0,38)\end{array}$ & $\begin{array}{c}0,63 \mathrm{~A} \\
( \pm 0,21)\end{array}$ & $\begin{array}{c}0,79 \mathrm{~A} \\
( \pm 0,26)\end{array}$ & \\
\hline
\end{tabular}

${ }^{1}$ Tratamentos: sal mineral (SAL); sal mineral proteinado (SMP), suplemento energético/protéico (SEP)

Médias seguidas de letras minúsculas distintas na mesma linha e letras maiúsculas na coluna, são diferentes $(\mathrm{P}<0,05)$ pelo Teste Tukey

Fonte: Elaboração dos autores.

Os altos valores de ganho de peso, observados para os três tratamentos no período inicial (junhojulho), podem ser decorrentes de um ganho compensatório. Antes de iniciar o experimento, os animais não recebiam suplementação e eram mantidos em pastagens com pouca disponibilidade e de baixa qualidade. Assim, quando os animais passam por um período de restrição e o crescimento é reduzido, o animal se recupera em taxas mais aceleradas, causando esse efeito denominado de ganho compensatório (EUCLIDES et al., 1998; GARCIA et al., 2004).

Outros fatores que levaram a altos desempenhos foram as altas disponibilidades de MV e LFV (Tabela 2) decorrentes da alta percentagem de lâminas foliares no início do experimento, além da forragem possuir, nesse período, melhor valor nutritivo (Tabela 3 ).
Porém, no segundo período que compreenderam os meses de julho a agosto os animais suplementados com SMP e com SEP ganharam mais peso $(\mathrm{P}<0,01)$ do que os animais que consumiram apenas sal mineral. Houve uma redução $(\mathrm{P}<0,01)$ muito drástica no ganho de peso dos animais que receberam SAL, entre os períodos, o que não foi verificado nos animais que foram suplementados SMP e SEP.

Desta forma, a redução no desempenho dos animais suplementados apenas com o sal mineral pode ser explicada pela ingestão insuficiente de nutrientes, ocasionada pela reduzida massa de forragem ofertada e de baixa qualidade, não sendo satisfatórias para o desenvolvimento adequado dos animais. Inversamente, os animais suplementados com SMP e SEP, obtiveram adequado ganho de peso mesmo com os efeitos adversos do período 
seco, devido ao consumo adequado de nutrientes fornecidos pelo suplemento (Tabela 4).

Goes et al. (2009) trabalhando com novilhos no período seco, em pastagens de $B$. brizantha cv Marandu notaram variação de 53,6\%; 29,6\%; 41,4\% e $162,6 \%$ no ganho de peso por hectare para os níveis de fornecimento de suplemento de 0,$125 ; 0,25 ; 0,5$ e $1,0 \%$ do peso vivo (PV), respectivamente, em relação ao ganho dos animais que receberam apenas suplemento mineral. Além do maior desempenho por animal, a suplementação no nível de 1,0\% PV proporcionou o maior ganho por área, com média de $106,73 \mathrm{~kg} \mathrm{ha}^{-1}$.

Pode-se observar também que houve um efeito combinado, aditivo/substitutivo, ou seja, houve diminuição do consumo de forragem pelo fornecimento de suplemento, mas ao mesmo tempo ocorreu melhora no desempenho animal. Com o consumo do suplemento, ocorre uma substituição, por parte do animal, de seu consumo de forragem, melhorando a quantidade da dieta ingerida, em razão da maior disposição de energia, que leva o animal a ser mais seletivo ao pastejar, ingerindo aquelas espécies ou as partes da forragem de melhor valor nutritivo (GOES et al., 2005).

Esses efeitos substitutivo (redução no consumo de forragem) e aditivo (aumento no ganho de peso dos animais) foram observados também por Simioni et al. (2009), Goes et al. (2010) e Porto et al. (2011), que trabalharam com recria de bovinos, no período da seca, em pastos de Brachiaria. Simioni et al. (2009) ainda comentaram que o maior CMST e a melhor qualidade nutricional de parte da matéria ingerida (suplemento) explicam o maior GMD.

Em revisão realizada por Silva et al. (2009), os pesquisadores concluíram que em todos os experimentos discutidos, a suplementação propiciou aos bovinos, maiores ganhos do que aqueles recebendo apenas sal mineral. Também comentaram que ocorre uma tendência linear crescente de aumento no GMD com o aumento da suplementação, mas isso ocorre geralmente até níveis de $0,8 \%$ do $\mathrm{PC}$ e, acima deste valor, embora ocorra melhora no ganho, estes aparentemente são menores. Há uma grande contribuição da disponibilidade de MST e de MV e da oferta de forragem, pois em níveis elevados, tendem a aumentar o ganho de peso independente do nível de suplementação.

Os dados observados nesse experimento, no segundo período de suplementação, estão de acordo com os observados por Euclides et al. (1998) na qual os novilhos em fase de terminação recebendo $0,8 \%$ do PV em suplemento ganharam $0,613 \mathrm{~kg} \mathrm{dia}^{-1} \mathrm{e}$ os animais que receberam apenas mistura mineral chegaram até mesmo a perder peso, na ordem de $70 \mathrm{~g} \mathrm{dia}^{-1}$.

Por outro lado, a suplementação em níveis mais altos pode se tornar uma alternativa de manejo para o período da seca, quando se desejar produzir uma elevada taxa de lotação ou aumentar a produção por área. Isso se torna possível pelo efeito substitutivo entre suplemento e forragem, proporcionando acúmulo de forragem disponível para os animais (GOES et al., 2009). Porto et al. (2011) também observaram que altas ofertas de suplementos reduzem o consumo de pasto, contudo aumentam o desempenho produtivo, devido à maior ingestão de energia durante o período seco, podendo resultar em maiores taxas de lotação.

\section{Conclusões}

No período da seca, em pastos de Brachiaria decumbens, o fornecimento de suplemento energético-protéico ao nível de $0,8 \%$ do PV, reduz o consumo de matéria seca de forragem, causando efeito substitutivo e diminui o tempo de pastejo dos animais. O suplemento energéticoprotéico e o sal mineral proteinado proporcionam efeito positivo sobre o ganho médio diário dos animais, evidenciando, assim, a necessidade de suplementação nesse período. 


\section{Agradecimentos}

À Universidade Estadual de Maringá, pela oportunidade do treinamento em nível de Doutorado do primeiro autor; à Empresa Brasileira de Pesquisa Agropecuária - Embrapa Gado de Corte, pela disponibilização da área e dos animais para execução do experimento.

\section{Referências}

BODINE, T. N.; PURVIS, H. T. Effects of supplemental energy and/or degradable intake protein on performance, grazing behavior, intake, digestibility, and fecal and blood indices by beef steers grazed on dormant native tallgrass prairie. Journal of Animal Science, Champaign, v. 81, n. 1, p. 304-317.

DIXON, R. M.; STOCKDALE, C. R. Associative effects between forages and grains: consequences for feed utilization. Australian Journal of Agricultural Research, Collingwood, v. 50, n. 3, p. 757-773, 1999.

EUCLIDES, V. P. B.; EUCLIDES FILHO, K.; ARRUDA, Z. J. de; FIGUEIREDO, G. R. Desempenho de novilhos em pastagens de Brachiaria decumbens submetidos a diferentes regimes alimentares. Revista Brasileira de Zootecnia, Viçosa, MG, v. 27, n. 2, p. 246-254, 1998.

EUCLIDES, V. P. B.; MACEDO, M. C. M.; OLIVEIRA, M. P. Avaliação de diferentes métodos de amostragem para se estimar o valor nutritivo de forragens sob pastejo. Revista Brasileira de Zootecnia, Viçosa, MG, v. 21, n. 4, p. 691-702, 1992.

EUCLIDES, V. P. B; CARDOSO, E. G.; MACEDO, M. G. M.; OLIVEIRA, M. P. de. Consumo voluntário de Brachiaria decumbens cv. Basilisk e Brachiaria brizantha cv. Marandu sob pastejo. Revista Brasileira de Zootecnia, Viçosa, MG, v. 29, n. 6, p. 2200-2208, 2000.

GARCIA, J.; ALCALDE, C. R.; ZAMBOM, M. A.; MARTINS, E. N.; JOBIM, C. C.; ANDRADE, S. R. D. F.; PEREIRA, M. F. Desempenho de novilhos em crescimento em pastagens de Brachiaria decumbens suplementados com diferentes fontes energéticas no período da seca e transição seca-águas. Revista Brasileira de Zootecnia, Viçosa, MG, v. 33, n. 6, p. 2140-2150, 2004.

GOES, R. H. T. B. de; MANCIO, A. B.; ALVES, D. D.; ALVES, D. D.; LANA, R. P.; CECON, P. R.; FREITAS, T. B.; BRABES, K. C. S. Desempenho de novilhos mantidos em pastagens submetidos à suplementação protéica e protéico-energética, durante a época seca.
Revista Brasileira de Saúde e Produção Animal, Salvador, v. 10, n. 4, p. 907-916, 2009.

GOES, R. H. T. B. de; MANCIO, A. B.; LANA, R. P.; CECON, P. R.; ALVES, D. D.; FREITAS, T. B.; BRABES, K. C. S. Suplementação proteica e energética para novilhos em recria, durante o período da seca. Revista Brasileira de Saúde e Produção Animal, Salvador, v. 11, n. 4, p. 1081-1094, 2010.

GOES, R. H. T. B.; MANCIO, A. B.; LANA, R. P.; LEÃO, M. I.; ALVES, D. D.; SILVA, A. T. S. Recria de novilhos mestiços em pastagem de Brachiaria brizantha, com diferentes níveis de suplementação, na região Amazônica. Consumo e parâmetros ruminais. Revista Brasileira de Zootecnia, Viçosa, MG, v. 34, n. 5, p. 17301739, 2005.

HOPPER, J. T.; HOLLOWAY, J. W.; BUTTS JÚNIOR; W. T. Animal variation in chromiun sesquioxide excretion patterns of grazing cows. Journal of Animal Science, Champaign, v. 46, n. 4; p. 1098-1102, 1978.

LAZARINNI, I.; DETMANN, E.; SAMPAIO, C. B.; PAULINO, M. F.; VALADARES FILHO, S. D.; SOUZA, M. A. de; OLIVEIRA, F. A. Intake and digestibility in cattle fed low-quality tropical forage and supplemented with nitrogenous compounds. Revista Brasileira de Zootecnia, Viçosa, MG, v. 38, n. 10, p. 2021-2030, 2009.

LIMA, J. B. M. P.; RODRÍGUEZ, N. M.; MARTHA JÚNIOR, G. B.; GUIMARÃES JÚNIOR, R.; VILELA, L.; GRAÇA, D. S.; SALIBA, E. O. S. Suplementação de novilhos Nelore sob pastejo, no período de transição águas-seca. Arquivo Brasileiro de Medicina Veterinária e Zootecnia, Belo Horizonte, v. 64, n. 4, p. 943-952, 2012.

LIPPKE, H.; ELLIS, W. C.; JACOBS, B. F. Recovery of indigestible fiber from feces of sheep and cattle on forage diets. Journal of Dairy Science, Champaign, v. 69, n. 2, p. 403-412, 1986.

MARTEN, G. C.; SHENK, J. S.; BARTON II, F. E. Nearinfrared reflectance spectroscopy (NIRS), analysis of forage quality. Washington: USDA, ARS, 1989. 110 p. (Agriculture handbook, 643).

MINSON, D. C. Forage in ruminant nutrition. Queensland: Academic Press, 1990. 483 p.

MOORE, J. E.; BRANT, M. H.; KUNKLE, W. E.; HOPKINS, D. I. Effects of supplementation on voluntary forage intake, diet digestibility, and animal performance. Journal of Animal Science, Champaign, v. 77, n. 1, p. 122-135, 1999.

MORAES, E. H. B. K.; PAULINO, M. F.; ZERVOUDASKIS, J. T.; VALADARES FILHO, S. C.; MORAES, K. A. K. de. Avaliação qualitativa da pastagem 
diferida de Brachiaria decumbens Stapf., sob pastejo, no período da seca, por intermédio de três métodos de amostragem. Revista Brasileira de Zootecnia, Viçosa, MG, v. 34, n. 1, p. 30-35, 2005.

MORAES, E. H. B. K. de; PAUlinO, M. F.; ZERVOUDASKIS, J. T.; DETMANN, E.; VALADARES FILHO, S. C.; MORAES, K. A. K. de. Aspectos produtivos e econômicos de novilhos mestiços alimentados com suplementos proteico-energéticos contendo uréia. Revista Brasileira de Zootecnia, Viçosa, MG, v. 41, n. 5, p. 1278-1284, 2012.

NATIONAL RESEARCH COUNCIL - NRC. Nutrient requirements of beef cattle. 7. ed. Washington: DC.: Academic Press, 1996. 242 p.

PORTO, M. O.; PAULIN O, M. F.; DETMANN, E.; VALADARES FILHO, S. C.; SALES, M. F. L.; CAVALI, J.; NASCIMENTO, J. C.; ACEDO, T. S. Ofertas de suplementos múltiplos para tourinhos Nelore na fase de recria em pastagens durante o período da seca: desempenho produtivo e características nutricionais. Revista Brasileira de Zootecnia, Viçosa, MG, v. 40, n. 11, p. 2548-2557, 2011.

PORTO, M. O.; PAULINO, M. F.; VALADARES FILHO, S. C.; SALES, M. F. L.; LEÃO, M. I.; COUTO, V. R. Fontes suplementares de proteína para novilhos mestiços em recria em pastagens de capim-braquiária no período das águas: desempenho produtivo e econômico. Revista Brasileira de Zootecnia, Viçosa, MG, v. 38, n. 8, p. 1553-1560, 2009.

SANTOS, E. D. G.; PAULINO, M. F.; QUEIROZ, D. S.; VALADARES FILHO, S. C.; FONSECA, D. M. da; LANA, R. P. Avaliação de pastagem diferida de Brachiaria decumbens Stapf: 1. características químicobromatológicas da forragem durante a seca. Revista Brasileira de Zootecnia, Viçosa, MG, v. 33, n. 1, p. 203213, 2004.
SILVA, F. F. da; SÁ, J. F. de; SCHIO, A. R.; ÍTAVO, L. C. V.; SILVA, R. R.; MATEUS, R. G. Suplementação a pasto: disponibilidade e qualidade $\mathrm{x}$ níveis de suplementação $\mathrm{x}$ desempenho. Revista Brasileira de Zootecnia, Viçosa, MG, v. 38, p. 371-389, 2009. Suplemento especial.

SIMIONI, F. L.; ANDRADE, I. F.; LADEIRA, M. M.; GONÇALVES, T. M.; MATA JÚNIOR, J. I. da; CAMPOS, F. R. Níveis e frequência de suplementação de novilhos de corte a pasto na estação seca. Revista Brasileira de Zootecnia, Viçosa, MG, v. 38, n. 10, p. 2045-2052, 2009.

STOBBS, T. H. Automatic measurement of the grazing time by dairy cows on tropical grass and legume pastures. Tropical Grassland, Queensland, v. 4, n. 3, p. 237-244, 1970.

TITGEMEYER, E. C.; DROUILLARD, J. S.; GREENWOOD, R. H.; RINGLER, J. W.; BINDEL, D. J.; HUNTER, R. D.; NUTSCH, T. Effect of forage quality on digestion and performance responses of cattle to supplementation with cooked molasses blocks. Journal of Animal Science, Champaign, v. 82, n. 2, p. 487-494, 2004.

WILLIAMS, C. H.; DAVID, D. J.; ISMAA, O. The determination of chromic oxide in feces samples by atomic absorption spectrophotometry. Journal of Agricultural Science, Toronto, v. 59, n. 3, p. 81-385, 1962.

ZERVOUDASKIS, J. T.; PAULINO, M. F.; DETMANN, E.; VALADARES FILHO, S. C.; LANA, R. P.; CECON, P. R. Desempenho de novilhas mestiças e parâmetros ruminais em novilhos, suplementados durante o período das águas. Revista Brasileira de Zootecnia, Viçosa, MG, v. 31 , n. 2 , p. 1050-1058, 2002. Suplemento. 